\title{
ELETRODOS ÍON-SELETIVOS: HISTÓRICO, MECANISMO DE RESPOSTA, SELETIVIDADE E REVISÃO DOS CONCEITOS
}

\author{
Julio Cesar Bastos Fernandes e Lauro Tatsuo Kubota* \\ Instituto de Química, UNICAMP, CP 6154, 13083-970 Campinas - SP \\ Graciliano de Oliveira Neto \\ Centro de Ciências Biológicas e da Saúde, USF, 12900-000 Bragança Paulista - SP
}

Recebido em 18/2/00; aceito em 11/5/00

\begin{abstract}
ION-SELECTIVE ELECTRODES: HISTORICAL, MECHANISM OF RESPONSE, SELECTIVITY AND CONCEPT REVIEW. This paper presents a review of the concepts involved in the working mechanism of the ion-selective electrodes, searching a historical overview, moreover to describe the new advances in the area.
\end{abstract}

Keywords: ion-selective electrodes; mechanism of response; potentiometry.

\section{INTRODUÇÃO}

A potenciometria é uma técnica bem conhecida dos químicos, sendo os eletrodos íon-seletivos (ISEs), somente uma pequena parte deste campo da eletroanalítica. A base da potenciometria foi estabelecida por Nernst, em 1888, descrevendo a origem do potencial de eletrodo entre um metal e uma solução contendo íons deste metal, e o potencial redox entre um metal inerte e uma solução contendo um sistema redox ${ }^{1}$. No início do século XX, em geral era grande a necessidade de quantificar o grau de acidez, o que fez com que houvesse uma corrida para pesquisa nesta área. O primeiro sensor potenciométrico usado para medir a acidez de uma solução aquosa foi o eletrodo de hidrogênio, proposto por Nernst, em $1897^{2}$, mas que devido à sua complexidade não tinha finalidade prática. Em 1906, Cremer ${ }^{3}$ desenvolveu o eletrodo de vidro para as medidas de acidez, sendo posteriormente aperfeiçoado por Haber e Klemensiewicz ${ }^{4}$. No entanto, havia dois problemas a serem superados na medida de acidez: definir as unidades e melhorar a instrumentação de modo a ter uma leitura mais reprodutível. Curiosamente, o aperfeiçoamento tecnológico do eletrodo de vidro se originou na comunidade acadêmica, enquanto que a fundamentação teórica, sobre as unidades de medida de acidez, surgiu da indústria. Sörensen, trabalhando para a empresa Carlsberg, foi quem propôs a escala de $\mathrm{pH}$, devido a necessidade de definir a influência da acidez sobre uma série de reações enzimáticas ${ }^{5}$. Quase ao mesmo tempo, as empresas Beckman e Radiometer comercializaram, o primeiro medidor de $\mathrm{pH}$, em $1935^{6,7}$, provavelmente, inspiradas no trabalho pioneiro de Elder e Wright ${ }^{8}$ sobre medidas de $\mathrm{pH}$ com eletrodo de vidro e potenciômetro de tubo à vácuo. Assim, a cooperação entre indústria e academia contribuiu para o desenvolvimento da potenciometria, tornando-a uma técnica consagrada e focada na medida de $\mathrm{pH}^{5}$.

Apesar da potenciometria ter surgido no fim do século XIX, a era de ouro dos ISE ocorreu à partir de 1957, com os trabalhos teóricos de Eisenman e Nikolski ${ }^{9,10}$. A primeira grande revolução na construção dos ISE pode ser atribuída a Ross ${ }^{11-}$ 13. Em 1966, trabalhando para empresa Orion, ele propôs um novo conceito de eletrodo para cálcio, o de membrana líquida, e posteriormente desenvolveu em conjunto com Frant ${ }^{12}$, o que seria um dos ISE mais empregados mundialmente até hoje, depois do eletrodo de vidro, o eletrodo de fluoreto à base de

E-mail: kubota@iqm.unicamp.br cristal de $\mathrm{LaF}_{3}$. Concomitantemente, Stefanec e Simon ${ }^{14,15}$ descobriram a possibilidade de utilizar polipeptídeos como materiais eletroativos, denominados de carregadores neutros. Este trabalho culminou com a utilização da valinomicina para construção do ISE para potássio, o qual apresentava uma impressionante seletividade para este íon, frente aos outros íons de metais alcalinos ou amônio. A segunda revolução ocorreu em 1970, no País de Gales, com Moody, Oke e Thomas ${ }^{16}$, que usaram pela primeira vez, eletrodos de membrana líquida à base do polímero PVC. A introdução do PVC como material de membrana simplificou bastante a construção dos ISE. A importância destes trabalhos é demonstrada pelo fato de que o ISE-K baseado em valinomicina e matriz de PVC, é atualmente, utilizado em quase todos os analisadores clínicos comercializados 5 . Dentro desde contexto, o desenvolvimento dos ISEs-Enzimáticos ${ }^{17}$, causou a terceira grande revolução nos ISE, permitindo que os sensores potenciométricos pudessem ser utilizados na medida de substâncias biológicas não iônicas. Estes dispositivos, comumente designados como biossensores, se baseiam na imobilização de um material biologicamente ativo, em geral enzimas, sobre a superfície de um transdutor, neste caso, um ISE que responda para a espécie formada na reação enzimática. Finalmente, pode-se considerar que a última revolução dos ISE ocorreu com o desenvolvimento do transistor de efeito de campo sensível à íon (ISFET) ${ }^{18}$. A importância dos ISFET pode ser atribuída à sua capacidade de miniaturização e a possibilidade de usar os processos da microeletrônica na sua microfabricação. Isto permitiria a produção em massa destes sensores, os quais poderiam ser empregados na monitoração de espécies de interesse in vivo ${ }^{19}$. Uma cronologia do desenvolvimento dos eletrodos íon-seletivos está apresentada na Figura 1.

A história da potenciometria e principalmente, com referência ao desenvolvimento e comercialização dos eletrodos íon-seletivos, é bem mais ampla do que aqui abordada, e maiores detalhes podem ser obtidos nos artigos de Janata ${ }^{19}$, Thomas ${ }^{20}$, Frant ${ }^{21,22}$, Ruzicka $^{5}$ e Pungor ${ }^{23}$ ou em monografias ${ }^{24,25}$ sobre o assunto.

Durante quase um século, desde o aparecimento do eletrodo de vidro $^{3}$, surgiram muitas controvérsias para explicar o mecanismo de funcionamento dos ISE baseados em membranas. Inicialmente, o mecanismo mais difundido era aquele baseado no potencial de Donnan ${ }^{26}$, onde uma distribuição desigual de íons entre duas fases separadas por uma membrana semi-permeável ocorria quando os íons eram capazes de permear a membrana, provocando assim, um equilíbrio eletroquímico e conseqüentemente, um potencial elétrico era estabelecido entre 


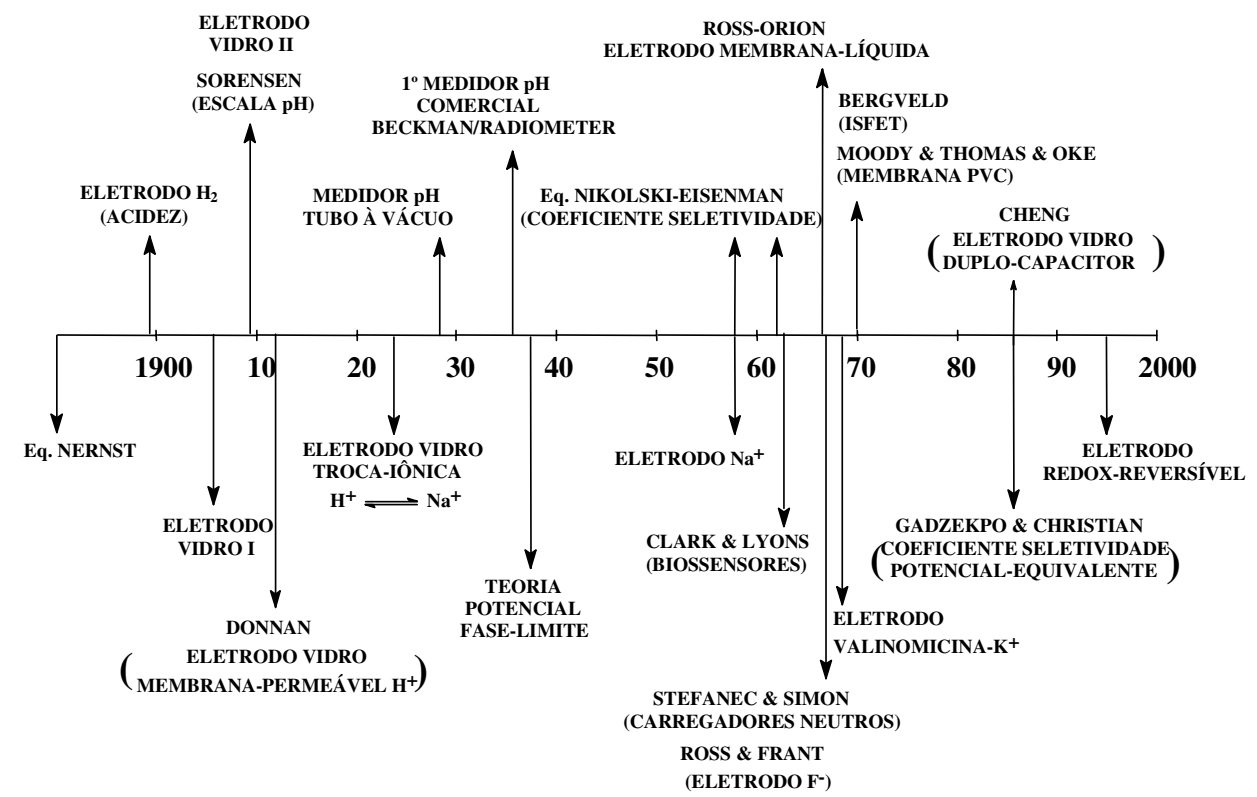

Figura 1. Cronologia do desenvolvimento da potenciometria e dos eletrodos íon-seletivos.

os dois lados da membrana. Contudo, o mecanismo mais difundido foi o baseado na teoria de troca iônica entre os íons $\mathrm{Na}^{+}$na camada de gel da membrana de vidro com os íons $\mathrm{H}^{+}$ na solução ${ }^{27,28}$. Em $1935-36$, Teorell ${ }^{29}$, Meyer e Sievers ${ }^{30}$ provaram que o mecanismo de troca iônica não poderia explicar o desenvolvimento do potencial num ISE, e propuseram o potencial de fase-limite (boundary-potential), contudo eles mantiveram os conceitos teóricos de membrana porosa contendo cargas em sítios fixos. Posteriormente, Pungor e Tóth ${ }^{31}$ assumiram que o potencial se desenvolvia somente na superfície do eletrodo. Atualmente, o conceito da dupla-camada elétrica e duplo capacitor, com ênfase na interface eletrodo-solução tem sido a proposta mais recente para explicar o desenvolvimento do potencial elétrico nos ISEs ${ }^{24}$. Assim, os princípios básicos de funcionamento de um ISE estão diretamente associados, com o que ocorre na interface eletrodo-solução. Contudo, ainda hoje se observam livros textos que não descrevem as várias teorias sobre o mecanismo de funcionamento de um ISE. Neste sentido, procurar-se-á aqui, divulgar as novas propostas, de modo que estes conceitos contribuam com a comunidade científica em seus cursos de eletroquímica e eletroanalítica.

\section{A INTERFACE ELETRODO-SOLUÇÃO}

Os modelos de interface eletrodo-solução foram inicialmente desenvolvidos para compreender os processos que ocorrem nas técnicas voltamétricas, onde o potencial é aplicado ao eletrodo de trabalho. A constante de proporcionalidade entre o potencial aplicado e a carga devida às espécies ordenadas na região interfacial na solução é a capacitância desta camada. Esta constante pode ser medida por técnicas de impedância ${ }^{32}$, mas no início era feita por eletrocapilaridade, essencialmente desenvolvida para o eletrodo de mercúrio e baseada na medida da tensão superficial. Os resultados obtidos com as técnicas de eletrocapilaridade aplicada ao eletrodo de mercúrio foram as bases para a elaboração dos primeiros modelos teóricos que tentavam prever as curvas de capacitância diferencial em função do potencial aplicado para diferentes concentrações de eletrólito $(\mathrm{NaF})$ e as de tensão superficial em função da variação de potencial.

$\mathrm{O}$ primeiro modelo para descrever o comportamento na interface eletrodo-solução foi sugerido por Helmholtz ${ }^{33,34}$. Nele as cargas positivas e negativas estavam ordenadas de um modo rígido nos dois lados da interface, o que deu origem à designação de camada compacta. Este modelo também foi desenvolvido paralelamente por Perrin, e sua análise é comparável ao funcionamento de um capacitor de placas paralelas. No entanto, este modelo não levava em consideração, as interações que ocorriam além da primeira camada de íons adsorvidos e não previa a variação da capacitância diferencial $\left(\mathrm{C}_{\mathrm{d}}\right)$ com o potencial, nem a dependência do potencial com a concentração ${ }^{35}$. Entre 1910 e 1913 , Gouy e Chapman ${ }^{36,37}$ desenvolveram independentemente, um modelo de dupla camada onde consideravam que o potencial e a concentração influenciavam a capacitância da dupla camada, assim, esta não seria compacta como na descrição de Helmholtz-Perrin, mas de espessura variável, estando os íons livres para se movimentarem. No entanto, este modelo, denominado de carga-difusa, apesar de não explicar integralmente os dados experimentais, mas foi a primeira contribuição na qual todos os aspectos essenciais da interface eletrodo-solução foram considerados. Em 1924, Stern ${ }^{38}$ combinou o modelo proposto por Helmholtz-Perrin, da camada compacta de íons com o de Gouy-Chapman, onde os íons estão dispersos na solução como uma nuvem em desordem térmica. As equações que descrevem o modelo misto envolvem contribuições individuais dos modelos de Helmholtz-Perrin e Gouy-Chapman. Considerando inicialmente, a região linear devida a Helmholtz-Perrin, tem-se pela equação de Lippman, que relaciona a tensão superficial $(\gamma)$ e as mudanças de potencial na interface $(\Delta \phi)^{32,35}$ :

$\frac{\partial \gamma}{\partial \Delta \phi}=-q_{M}=q_{S}$

onde $\theta$ é a carga no metal (M) e na solução (S).

Admitindo a equivalência entre a interface eletrificada na dupla camada e a teoria eletrostática para os capacitores de placas paralelas, pode-se postular o modelo de HelmholtzPerrin. $O$ potencial $(\phi)$ que cruza o capacitor é dado por ${ }^{35}$ :

$\phi=\frac{\mathrm{q}}{\mathrm{C}}=\frac{\mathrm{q}}{\mathrm{A \varepsilon} / \mathrm{d}}$

onde d e A são a distância entre as placas e a área das mesmas, respectivamente e $\varepsilon$ é a constante de permissividade do material entre as placas (Faraday $\mathrm{m}^{-1}$ ou $\mathrm{C}^{2} \mathrm{~N}^{-1} \mathrm{~m}^{-2}$ ).

Substituindo na Eq. 1 para uma variação de potencial num determinado instante, e integrando, tem-se: 
$\int \gamma=-\frac{d}{A \varepsilon} \int q_{M} d q_{M}$

ou

$\gamma+$ cte $=-\frac{\mathrm{d}}{\mathrm{A \varepsilon}} \frac{1}{2} \mathrm{q}_{\mathrm{M}}^{2}$

Quando a carga no metal é igual a zero, a tensão superficial é máxima e então esta variará com o potencial de acordo $\operatorname{com}^{35}$ :

$\gamma=\gamma_{\max }-\frac{\mathrm{d}}{\mathrm{A \varepsilon}} \frac{1}{2} \mathrm{q}_{\mathrm{M}}^{2}$

ou

$\gamma=\gamma_{\max }-\frac{\mathrm{d}}{\mathrm{A} \varepsilon} \frac{1}{2} \phi^{2}$

sendo a equação (6) obtida da substituição de (2) em (5).

Como consequiência do modelo de Gouy-Chapman, a carga na solução no modelo de Stern seria dada por:

$\mathrm{q}_{\mathrm{S}}=\mathrm{q}_{\mathrm{HP}}+\mathrm{q}_{\mathrm{GC}}$

onde $\mathrm{q}_{\mathrm{s}}$ é a carga na solução, $\mathrm{q}_{\mathrm{HP}}$ é a carga devida ao modelo de Helmholtz-Perrin e $\mathrm{q}_{\mathrm{GC}}$ é a carga devida ao modelo de Gouy-Chapman.

Isto implica em dois potenciais, o primeiro devido ao metal $\left(f_{M}\right)$ e ao plano de Helmholtz-Perrin $\left(f_{H P}\right)$, e o segundo potencial devido à carga na solução $\left(\mathrm{f}_{\mathrm{S}}\right)$. De maneira geral seria:

$\phi_{\mathrm{M}}-\phi_{\mathrm{S}}=\left(\phi_{\mathrm{M}}-\phi_{\mathrm{HP}}\right)+\left(\phi_{\mathrm{HP}}-\phi_{\mathrm{S}}\right)$

A distinção entre $\left(\phi_{\mathrm{M}}-\phi_{\mathrm{HP}}\right)$ e $\left(\phi_{\mathrm{HP}}-\phi_{\mathrm{S}}\right)$ é a síntese dos modelos da camada compacta com o da difusa. Assim, no modelo de Stern, a variação de potencial que cruza uma interface, consiste de duas regiões, uma linear correspondente aos íons em contacto com o eletrodo $\left(\phi_{\mathrm{M}}-\phi_{\mathrm{HP}}\right)$ e uma exponencial $\left(\phi_{\mathrm{HP}}-\right.$ $\left.\phi_{S}\right)$, correspondendo aos íons que sofrem a influência combinada da força elétrica ordenada com a desordem das forças térmicas $^{32,35}$. Porém, outra conseqüência do modelo de Stern é que a interface eletrificada é equivalente a dois capacitores em série. Logo a capacitância diferencial é dada por $^{35}$ :

$\frac{1}{\mathrm{C}_{\mathrm{d}}}=\frac{1}{\mathrm{C}_{\mathrm{HP}}}+\frac{1}{\mathrm{C}_{\mathrm{GC}}}$

$\mathrm{ou}$

$\frac{1}{\mathrm{C}_{\mathrm{d}}}=\frac{\mathrm{x}_{\mathrm{H}}}{\varepsilon_{\mathrm{r}} \varepsilon_{\mathrm{o}}}+\frac{1}{\sqrt{2\left(\varepsilon_{\mathrm{r}} \varepsilon_{\mathrm{o}} \mathrm{z}^{2} \mathrm{e}_{0}^{2} \mathrm{n}_{\mathrm{i}}^{0} / \mathrm{k}_{\mathrm{B}} \mathrm{T}\right) \cosh \left(\mathrm{ze}_{0} \phi_{\Delta} / 2 \mathrm{k}_{\mathrm{B}} \mathrm{T}\right)}}$

onde $\varepsilon_{\mathrm{r}}$ é a constante de permissividade relativa que é suposto não variar com a distância e $\varepsilon_{0}$ constante de permissividade no vácuo e vale $8,8510^{-12} \mathrm{~F} \mathrm{~m}^{-1} ; \mathrm{x}_{\mathrm{H}}$ é a distância de aproximação máxima das cargas, as quais por serem tratadas como cargas pontuais correspondem ao raio iônico; $\mathrm{z}$ é a carga do íon; $\mathrm{e}_{\mathrm{o}}$ é a carga do elétron; $\mathrm{n}_{\mathrm{i}}^{\mathrm{o}}$ é a concentração numérica de íons no interior da solução; $\mathrm{k}_{\mathrm{B}}$ é a constante de Boltzman $\left(1,3810^{-23} \mathrm{~J} \mathrm{~K}^{-1}\right)$; $\mathrm{T}$ a temperatura $(\mathrm{K})$; $\phi_{\Delta}$ é o potencial quando a distância entre a interface eletrodo-solução é zero.
Assim, a variação da capacitância diferencial total com o potencial, obedece a dois casos:

- Próximo de $\mathrm{E}_{\mathrm{z}}, \mathrm{C}_{\mathrm{HP}} \gg \mathrm{C}_{\mathrm{GC}}$ e $\mathrm{C}_{\mathrm{d}} \cdot \mathrm{C}_{\mathrm{GC}}$;

Afastado de Ez, $\mathrm{C}_{\mathrm{HP}} \ll<\mathrm{C}_{\mathrm{GC}}$ e $\mathrm{Cd}$. $\mathrm{C}_{\mathrm{HP}}$.

sendo que Ez é o potencial quando a carga é zero.

Para o caso de soluções suficientemente concentradas, a capacitância da interface é efetivamente igual a capacitância de Helmholtz-Perrin $\left(\mathrm{C}_{\mathrm{HP}}\right)$. Isto significa que para soluções concentradas a maior parte da carga na solução está comprimida dentro do plano de Helmholtz-Perrin, ou seja, pouca carga está dispersa na solução. Quando a solução é diluída (concentração baixa) a capacitância torna-se essencialmente devida ao modelo proposto por Gouy-Chapman, onde a carga dispersa na solução sofre influência simultânea das forças elétricas e térmicas. Contudo, o modelo de Stern, nada mais é que uma consideração dos modelos da camada compacta e difusa, sendo uma boa aproximação para o eletrodo de mercúrio (eletrodo líquido), porém, ele não previa o comportamento de outros eletrodos, principalmente os sólidos ${ }^{32}$, além de não levar em consideração a influência das moléculas do solvente ${ }^{35}$.

Outro modelo foi então proposto em 1947, por Grahame ${ }^{39}$. Este modelo era constituído de três regiões e a principal diferença entre ele e o anterior é a adsorção específica. Um íon especificamente adsorvido perde sua solvatação aproximando-se mais da superfície do eletrodo. Além disso, o íon pode ter a mesma carga do eletrodo ou oposta, mas a interação é forte. Baseado neste modelo, Bockris, Devanathan e Müller ${ }^{40}$ propuseram um modelo mais preciso. Em solventes dipolares, como a água, existe uma interação entre eletrodos e dipolos. Um fato que corrobora isto, é que a concentração do solvente é muito maior que a concentração do soluto. No caso da água, a concentração é de $55,5 \mathrm{~mol} \mathrm{~L}^{-1}$. Este modelo mostra a predominância de moléculas da água próximo à interface eletrodo-solução ( $\mathrm{Fi}$ gura 2). Os dipolos se orientam de acordo com a carga do eletrodo, formando uma camada com os íons adsorvidos. Considerando o eletrodo como um "íon gigante", as moléculas do solvente formam a sua primeira camada no plano interior de Helmholtz (IHP), que é o plano passando através dos dipolos e dos íons especificamente adsorvidos no eletrodo. O plano exterior de Helmholtz (OHP) refere-se a adsorção de íons solvatados, que seria devido a uma segunda camada de solvatação e fora deste viria a camada difusa. Neste modelo foi definido um novo plano, o de cisalhamento, que poderia coincidir ou não com o OHP. Este plano, importante na compreensão dos efeitos electrocinéticos limita a região onde a fixação rígida de íons devido à carga do eletrodo, pára de operar. O potencial deste plano é denominado de zeta ou eletrocinético $(\zeta)$.

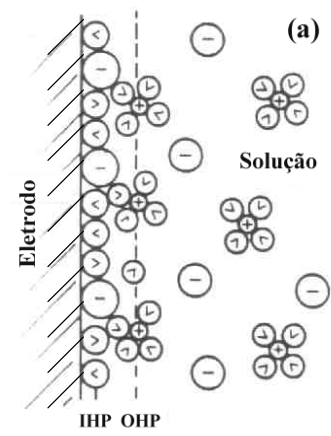

(a)

(b)

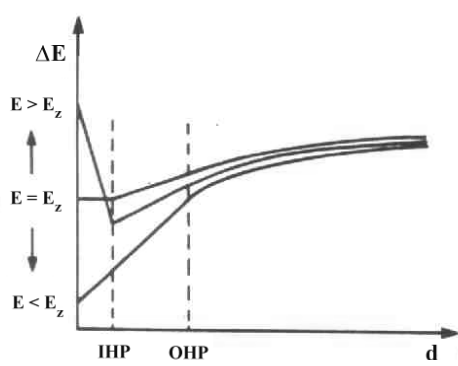

Figura 2. (a) Modelo de Bockis et al. ${ }^{35,40}$ para representar a dupla camada, com a distribuição dos íons e moléculas do solvente (o símbolo () representa a molécula de água); (b) Variação do potencial eletrostático em função da distância ao eletrodo.

Os modelos apresentados anteriormente dão ênfase às considerações eletrostáticas, no entanto, os mais recentes levam 
também em consideração a distribuição eletrônica dos átomos no eletrodo, relacionando com a sua função trabalho. Modelos deste tipo foram primeiro desenvolvidos por Damaskin e Frumkin $^{41}$ e só foram possíveis depois de uma série de estudos com eletrodos sólidos. Por outro lado, a região interfacial de um metal até o IHP tem sido considerada como um capacitor eletrônico molecular ${ }^{32}$ e este modelo tem explicado muitos resultados experimentais. Outro modelo importante é o de "Jellium", onde os defeitos da face cristalográfica e a diferença entre metais demonstram que o decaimento de todo o potencial a partir da interface eletrodo-solução para o interior da solução está incorreto. O potencial começa a decair ainda no interior do eletrodo e reflete o fato de os elétrons do sólido penetrarem uma pequena distância na solução devido as propriedades ondulatórias do elétron. Neste modelo, o potencial de Galvani ou elétrico interior $(\phi)$ e o potencial de Volta ou elétrico exterior $(\Psi)$, que é o potencial fora da distribuição eletrônica do eletrodo ( $\cong$ no IHP à $10^{-5} \mathrm{~cm}$ da superfície) são distintos um do outro. A diferença entre estes potenciais é o potencial de superfície $(\chi)^{32}$. Recentemente, Gonzalez e Sanz ${ }^{42}$ propuseram uma nova teoria sobre a camada difusa levando em consideração os potenciais químicos das espécies iônicas na solução. Damanski e Grafov ${ }^{43}$ testaram esta nova teoria com os dados experimentais obtidos para capacitância do eletrodo de mercúrio em soluções aquosas de sulfato de sódio ou lantânio, e os dados concordaram melhor com o novo modelo do que o proposto por Gouy-Chapman-Grahame-Bockris.

O conceito da estrutura da dupla camada ainda não está bem estabelecido e vários estudos vêm sendo realizados para elucidar esta teoria ${ }^{44-49}$. Brett e Brett ${ }^{32}$ descrevem as técnicas espectroscópicas in situ, como infravermelho e Raman, como as principais técnicas que podem contribuir para uma compreensão melhor da interface eletrodo-solução. Por outro lado, vários pesquisadores têm estudado ISE de estado sólido e com trocadores iônicos ou preparados à partir de carregadores neutros (ionóforos) incorporados em matriz de PVC com plastificante, através de técnicas de impedância ${ }^{50-54}$. Estas medidas revelaram primeiramente a resistência devido ao tamanho do eletrodo e a capacitância da membrana. Outras técnicas de perturbação elétrica têm sido utilizadas para estudar os ISE, como a cronopotenciometria ${ }^{55,56}$ e cronoamperometria $^{57,58}$, esta última principalmente para investigar as membranas preparadas com PVC e plastificante, enquanto que a voltametria cíclica tem sido muito empregada nos estudos de transferência iônica interfacial por carregadores neutros ${ }^{59,60}$. Estudos mais recentes levam em consideração a teoria aplicada aos semicondutores ${ }^{32}$, onde circuitos eletrônicos equivalentes têm sido propostos para interpretar a interface de eletrodos íon-seletivos elaborados em semicondutores, como por exemplo, para íons potássio, baseados em valinomicina-platificantePVC recobrindo eletrodos de $\mathrm{Si}$ com finas camadas de $\mathrm{Si}_{3} \mathrm{~N}_{4} /$ $\mathrm{SiO}_{2}{ }^{61}$. A técnica de perturbação da concentração, denominada de medida do tempo de resposta, também têm sido muito empregada nos estudos com ISE ${ }^{62-64}$.

\section{O MECANISMO DE RESPOSTA DOS ELETRODOS ÍON-SELETIVOS}

Os modelos de interface eletrodo-solução, apesar de não estarem inteiramente elucidados, contribuem para compreensão do mecanismo de funcionamento dos eletrodos íon-seletivos. Processos eletroquímicos, freqüentemente se dividem em processos parciais caracterizados por suas velocidades, as quais são limitadas pela resistência ao processo. Nesses processos, ocorrem acúmulo de cargas em camadas, que podem ser representadas como capacitores. Então, o circuito eletrônico equivalente para uma interface eletrificada é um capacitor associado em paralelo com um resistor (Figura 3$)^{35}$. Para uma interface idealmente polarizável a resistência tende ao infinito, enquanto para a interface não-polarizável a resistência tende a zero. Quando o circuito é conectado à uma fonte de tensão, se a resistência é muito elevada, o capacitor se carrega até o valor de potencial da fonte. Este é o comportamento da interface polarizável. Caso a resistência em paralelo com o capacitor seja baixa, então qualquer tentativa para mudar o potencial que passa através do capacitor é compensada pelo escoamento de cargas através do caminho de baixa resistência, que nada mais é que o comportamento da interface não-polarizável. $\mathrm{O}$ que faz com que a interface decida resistir (interface nãopolarizável) ou aceitar mudanças de potencial (interface polarizável) é a velocidade com que a transferência de cargas ocorre através da mesma ${ }^{35}$. O exemplo clássico de interface não-polarizável é o eletrodo de Calomelano ou melhor, os eletrodos utilizados como referência. Contudo, este modelo simplificado de circuito eletrônico, também deve levar em consideração os processos estáticos e dinâmicos que ocorrem em uma célula eletroquímica. Assim, Buck ${ }^{65}$ propôs que, um circuito equivalente para uma célula eletroquímica potenciométrica corresponderia a cinco circuitos RC paralelos ligados em série. Cada circuito RC seria devido as seguintes características: ao volume do eletrodo, a reação superficial, as reações de adsorção na superfície do eletrodo, a geração e recombinação das cargas carregadas e ao processo de difusão dos íons. Na prática, nas medidas potenciométricas, não é possível medir a diferença de potencial (ddp) absoluta que cruza uma interface eletrodo-solução e somente a ddp de um sistema de interfaces ou célula eletroquímica. Isto acontece porque na medida de potencial, o processo por si mesmo, isto é, a imersão dos eletrodos na solução, introduz diferenças de potencial, as quais são também medidas, e esta soma não pode representar a ddp desejada ${ }^{35}$, daí a necessidade nas medidas potenciométricas serem realizadas com um eletrodo de referência. Não se pode esquecer também, do potencial de junção líquida que ocorre nas interfaces com concentrações diferentes de eletrólito de mesma natureza. Por exemplo, no caso de duas soluções de $\mathrm{HCl}$, uma 0,1 e a outra $0,01 \mathrm{~mol} \mathrm{~L}^{-1}$ separadas por uma membrana porosa, haverá tendência de difusão dos íons $\mathrm{H}^{+}$e $\mathrm{Cl}^{-}$da solução mais concentrada para a mais diluída. Como a mobilidade dos íons $\mathrm{H}^{+}$é cerca de cinco vezes maior que a dos íons cloreto, eles se difundem mais rapidamente, fazendo com que a transferência de cargas da solução mais concentrada para a mais diluída resulte no aparecimento de um potencial de junção da ordem de $+40 \mathrm{mV}$. Daí os eletrodos de referência serem preenchidos com solução de $\mathrm{KCl}$ saturado $(4,2$ mol L $\mathrm{L}^{-1}$ à $25^{\circ} \mathrm{C}$ ), pois a mobilidade dos íons cloreto é apenas ligeiramente maior do que a dos íons potássio e assim, o potencial de junção é apenas da ordem de $-1 \mathrm{mV}$. Outro fator é o potencial de assimetria devido a irregularidade na construção da membrana ${ }^{66}$. Além disto, é importante lembrar que as medidas de potencial não podem ser realizadas com simples voltímetros. Estes aparelhos drenam uma quantidade de corrente substancial ( $\cong 1 \mathrm{~mA}$ ), e desde que o potencial na interface depende da corrente que passa através dela, esta situação pode originar um efeito no qual a medida do instrumento afeta e muda a quantidade que está sendo medida. Esta medida é então realizada com milivoltímetros eletrônicos que requerem correntes da ordem de $10^{-14} \mathrm{~A}$ e apresentam impedância de entrada de $10^{8} \Omega$. Alternativamente, um simples circuito de compensação, um galvanômetro ligado em série com uma resistência elevada $(\cong 1 \mathrm{M} \Omega)$, onde o potencial da célula eletroquímica é balanceado contra uma fonte de potencial externa até que a corrente que atravessa o galvanômetro seja nula ${ }^{35,66}$, pode também ser utilizado na medida do potencial de células eletroquímicas com eletrodos íon-seletivos.

$\mathrm{O}$ mecanismo de trabalho dos sensores íon-seletivo podem ser interpretados à luz dos conceitos citados anteriormente, sobre as medidas potenciométricas e modelos de interface eletrodo-solução. Para os eletrodos de primeira espécie (metal), a 
(a)

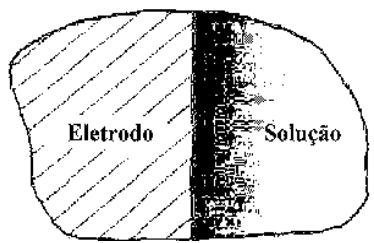

(b)

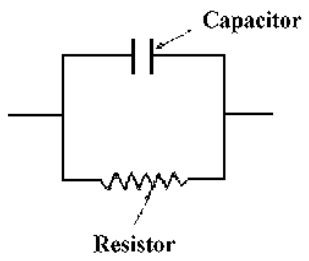

Figura 3. (a) Interface eletrificada eletrodo-solução (b) Circuito eletrônico equivalente, quando $R \rightarrow \infty$ a interface é polarizável e para $R \rightarrow 0$, a interface é não-polarizável.

transferência de elétrons era a etapa da reação determinante do potencial, porém esta explicação não era aplicável para os eletrodos de membrana, como por exemplo, o de vidro. A resposta veio alguns anos depois com os estudos realizados por Donnan $^{26}$. Ele separou duas soluções de haleto de metal alcalino por uma membrana semi-permeável. Se o eletrólito de um lado da membrana contém um íon que pode difundir através dela, uma distribuição desigual de íons permeáveis é observada, estabelecendo desta forma um equilíbrio eletroquímico e conseqüentemente, um potencial elétrico era estabelecido entre os dois lados da membrana. Apesar desta explicação ser plausível e clara para o fenômeno observado por Donnan, o conceito de difusão através da membrana de vidro por íons hidrogênio foi definitivamente contestada por Haugaard ${ }^{67}$, através de análise química e por Schwabe e Dahms ${ }^{68}$ com experimentos utilizando tritium. Em tais casos, nenhum fenômeno de difusão através da membrana de vidro foi observado. Outra proposta para o mecanismo de resposta do eletrodo de vidro foi então baseado na teoria de troca iônica. Neste caso, os íons $\mathrm{Na}^{+}$na camada de gel da membrana de vidro eram substituídos pelos íons $\mathrm{H}^{+}$na solução entrando em um equilíbrio quími$\mathrm{co}^{27,69,70}$. Contudo, tal conceito não foi suportado pelos resultados experimentais. Primeiramente, se tal fenômeno de troca iônica ocorresse, não poderia causar uma mudança nas cargas interfaciais, e conseqüentemente uma ddp não poderia ser desenvolvida. Por outro lado, os íons sódio na camada gel da membrana deveriam se esgotar depois de um longo tempo de uso do eletrodo de vidro, resultando no colapso do sensor ${ }^{24}$. Outros trabalhos nesta área ${ }^{63,71-75}$, mostraram definitivamente que o fenômeno de transporte por difusão através de uma membrana semi-permeável não poderia ser aplicado para explicar o potencial desenvolvido em uma membrana de vidro. Pungor $^{75,76}$, com o objetivo de examinar se o transporte de íons realmente poderia ser responsável pelo desenvolvimento do potencial, investigou as características físico-químicas de eletrodos de membrana contendo diferentes compostos. Ele observou que para transdutores metálicos ( $\mathrm{Pt}, \mathrm{Al}, \mathrm{Ag})$, as quais suas faces eram recobertas com uma membrana de borracha de silicone contendo iodeto de prata, o potencial desenvolvido não dependia do metal. Logo, uma lâmina de prata coberta com iodeto de prata, não poderia tomar parte no transporte de íons $\mathrm{Ag}^{+}$como era anteriormente suposto. Com o desenvolvimento de instrumentos adequados para a medida do tempo de resposta real de um eletrodo, os estudos realizados com o método de perturbação da concentração, mostraram que eletrodos de lâmina de prata, haletos de prata ou de potássio, onde este último contém um componente complexante para potássio incorporado numa membrana polimérica, apresentavam tempos de resposta em torno de $20 \mathrm{~ms}$. Isto indicava que o processo de difusão não deveria contribuir para a formação do potencial, uma vez que a difusão de íons através de uma membrana é muito menor que em solução, e o tempo para estabelecer o potencial deveria ser muito maior que aquele observado. Além disto, os eletrodos íon-seletivos para potássio, preparados a partir de diferentes agentes complexantes, valinomicina ou bis-éter-coroa, apresentavam o mesmo potencial para a mesma concentração de íons potássio na solução, indicando que somente o soluto era responsável pelo desenvolvimento do potencial elétrico.

Antes de definir o mecanismo baseado na teoria do capacitor é importante ter-se em mente alguns conceitos fundamentais para sua melhor compreensão. É bem conhecido que uma bateria ou pilha gera uma ddp através de uma reação redox. A bateria é um dispositivo que não contém isolante e possui um anodo e um catodo que estão imersos em um meio eletrolítico. Quando o anodo é conectado ao catodo por um circuito externo uma corrente elétrica flui até que a reação química cesse, sendo em sua maioria reações reversíveis, seguindo os princípios de equilíbrio termodinâmico, ou seja, a equação de Nernst. Contudo, é bem conhecido que nenhuma reação redox está envolvida no desenvolvimento do potencial em um eletrodo de vidro $^{24,67}$, pois caso isto ocorresse hidrogênio gasoso teria que ser produzido. Por outro lado, um capacitor eletrolítico é um dispositivo capaz de armazenar cargas elétricas, através de duas placas paralelas entre as quais há um isolante ou dielétrico, onde nenhuma reação redox reversível ocorre. Além disto, quando as placas carregadas são conectadas nenhuma corrente significativa flui, condição básica para a medida de ddp com eletrodos íon-seletivos. A ddp é proporcional a carga e uma constante denominada de capacitância (vide Eq. 2). Assim, um eletrodo de vidro, ou melhor, de membrana é mais comparável a um capacitor do que uma bateria ${ }^{24}$, sendo este conceito, o do capacitor eletrolítico, a base para compreensão do funcionamento dos ISE $^{24,77}$. A Figura 4 apresenta um modelo esquemático de um eletrodo de membrana baseado neste conceito. Quando um eletrodo de vidro é imerso em uma solução eletrolítica, uma dupla camada é formada, contendo cargas na superfície ${ }^{24}$. Desde que ambas as camadas, interna e externa, da membrana estão em contato com uma solução eletrolítica, duas dupla camadas são formadas, uma em cada lado da membrana. Considerando os modelos de interface eletrodo-solução apresentados anteriormente, em que uma dupla camada foi considerada como um capacitor, duas dupla camadas constituem um duplo-capacitor. A ddp é obtida pela diferença entre os potenciais na interface externa e interna. Um eletrodo capacitor pode ser considerado como uma membrana feita de qualquer material dielétrico ou semicondutor, o qual pode adsorver cátions e ânions em seus sítios ativos. $\mathrm{O}$ potencial de membrana é desenvolvido à partir das duas interfaces que armazenam cargas sobre a superfície através da adsorção na dupla camada. O eletrodo de vidro segue a Lei da Capacitância (Eq. 2), onde as características da membrana de vidro são dadas pela constante de permissividade $(\varepsilon)$, a área (A), a espessura (d), e a capacitância (C) da membrana. Quando estes fatores são constantes para uma mesma membrana de vidro, o potencial será proporcional a carga (q) adsorvida sobre a membrana ${ }^{24}$, de acordo com:

$\phi=K\left(\sum q_{+}-\sum q_{-}\right)$

onde $\mathrm{K}$ é uma constante que engloba todos os parâmetros citados anteriormente.

Caso, somente cátions estejam adsorvidos sobre a superfície da membrana, a q- $=0$, resultando no aumento do potencial com o aumento das cargas positivas. $\mathrm{O}$ inverso ocorre quando somente ânions estão adsorvidos, isto é, ocorre o decréscimo no potencial com o aumento das cargas negativas. Se ambas as cargas estão adsorvidas simultaneamente, o resultado é a soma das cargas positivas e negativas na superfície ${ }^{24}$. Tais evidências foram demonstradas por Cheng ${ }^{24}$ com simples experimentos. Ele elaborou um sensor cilíndrico de vidro sensível ao $\mathrm{pH}$ onde o tubo foi selado contendo tampão fosfato $\mathrm{pH}$ 7,0 e um eletrodo de referência $\mathrm{Ag} / \mathrm{AgCl}$. Então, a superfície externa do eletrodo cilíndrico foi exposta a diferentes soluções de $\mathrm{pH}$. Dependendo da área do 
(A)

(B)

(C)

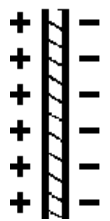

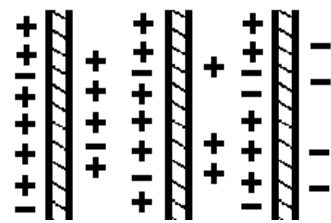

Figura 4. (A) Esquema de um capacitor de placas paralelas comumente usado em aparelhos eletrônicos, que é capaz de armazenar cargas quando um potencial é aplicado com uma bateria ou fonte de energia; (B) Modelo de um eletrodo de membrana; $(\boldsymbol{C})$ Representação de um eletrodo de vidro ou outro qualquer de membrana, o qual apresenta uma estrutura superficial zwitteriônica.

eletrodo imersa na mesma solução de pH, em soluções ácidas era observado um aumento do potencial com o aumento da área do eletrodo imersa, ocorrendo o fenômeno oposto em soluções alcalinas, onde ocorria um decréscimo no potencial com o aumento da área do eletrodo imersa. Assim, em meio ácido o potencial aumenta para valores mais positivos como função do aumento dos íons $\mathrm{H}^{+}$adsorvidos sobre a superfície do vidro, enquanto que em meio alcalino o potencial aumenta para valores mais negativos como função dos íons $\mathrm{OH}^{-}$. Esta é a diferença fundamental entre a teoria do eletrodo-capacitor com as teorias do passado, as quais não consideravam os íons $\mathrm{OH}^{-}$como regra no desenvolvimento do potencial. Similar experimento realizado com um eletrodo cilíndrico de vidro sensível aos íons $\mathrm{Na}^{+}$, observou-se que o potencial deslocava para valores mais negativos em soluções diluídas $\left(10^{-2}-10^{-5} \mathrm{~mol} \mathrm{~L}^{-1}\right)$ de nitrato de sódio em tampão de etilenodiamina, em $\mathrm{pH}$ 10,5, com o aumento da área imersa do eletrodo. Contudo, para as medidas realizadas com o mesmo tampão para concentrações de íon sódio acima de $1 \mathrm{~mol} \mathrm{~L}^{-1}$, o potencial permanecia praticamente constante ou aumentava para valores mais positivos com o aumento da área do eletrodo imersa. Isto mostra que o eletrodo de vidro para sódio também responde para $\mathrm{H}^{+}$e $\mathrm{OH}^{-}$e a sua superfície, é então, zwitteriônica podendo adsorver ao mesmo tempo os íons $\mathrm{Na}^{+}$e $\mathrm{OH}^{-}$. Então, o potencial desenvolvido é o resultado da diferença de cargas positivas e negativas adsorvidas como descrito na Eq. $11^{24}$.

Baseado nos conceitos e nas observações mencionadas anteriormente, de maneira geral, o potencial desenvolvido num sensor potenciométrico é causado pela separação de cargas na superfície do eletrodo. Esta interpretação está diretamente associada com processos de quimissorção do íon primário proveniente da solução para a superfície do eletrodo. No caso dos contra-íons, estes se acumulam na fase líquida, a solução, ocorrendo a separação de cargas. Assim, o potencial químico do soluto é o responsável pelo sinal eletroquímico ${ }^{75}$.

\section{A EQUAÇÃO DE BUTLER-VOLMER - A BASE DA ELETROQUÍMICA}

Agora procurar-se-á estabelecer as funções matemáticas que descrevem o método potenciométrico. As deduções a seguir são válidas para um eletrodo metálico, porém, são estendidas também aos eletrodos de membrana.

Ao introduzir-se um eletrodo metálico numa solução eletrolítica contendo íons deste metal, no instante da imersão, o metal está eletricamente neutro, uma vez que a carga total no metal é nula $\left(\mathrm{q}_{\mathrm{M}}=0\right)$ e também não há excesso de carga na solução $\left(\mathrm{q}_{\mathrm{s}}=0\right)$. Assim, na interface, a ddp bem como o campo elétrico são nulos, desprezando-se a orientação preferencial dos dipolos da água. A espontaneidade de uma dada reação à transferência de elétrons depende do sistema estar no estado de equilíbrio ou não, isto é, para que não ocorra transferência de carga através da interface, o sistema deve estar no estado de energia livre mínimo, o que corresponde à igualdade dos potenciais eletroquímicos $\left(\mu_{1}\right)$ das espécies na solução (s) e no eletrodo (e) que podem passar através da interface ${ }^{78}$ :

$\left(\bar{\mu}_{\mathrm{i}}\right)_{\mathrm{s}}=\left(\bar{\mu}_{\mathrm{i}}\right)_{\mathrm{e}}$

O potencial eletroquímico é o trabalho total necessário para transportar um mol de uma dada substância desde o infinito até um ponto no interior da interface. Ao tratarmos de uma interface eletrodo-solução, segundo o modelo de dupla camada elétrica e se a partícula em estudo for carregada, haverá influência das cargas positivas e negativas da interface, bem como dos dipolos do solvente. Logo, o trabalho total executado será a soma do trabalho elétrico com o trabalho químico, este último devido às interações íon-solvente, íon-íon e às interações solvente-solvente. Então, o potencial eletroquímico da espécie $(i)$ será $^{78}$ :

$\bar{\mu}_{\mathrm{i}}=\mu_{\mathrm{i}}+\mathrm{zF} \Delta \phi$

onde $\Delta \phi$ é a diferença de potencial da interface eletrificada.

Assim, o gradiente de potencial eletroquímico dá origem ao transporte de espécies com carga, por meio de um mecanismo envolvendo difusão e condução dos íons da solução. Se o campo elétrico é nulo, a igualdade dos potenciais eletroquímicos resumese à igualdade dos potenciais químicos, e estando a interface em equilíbrio, os potenciais químicos da espécie (i) são iguais em ambos os lados da interface. Seguindo este raciocínio, por questão de simplicidade será considerado que o íon positivo, $\mathrm{A}^{+}$move alguns ângstrons através da dupla camada, vindo da solução para a superfície do metal. Não é importante saber se os elétrons se movem do eletrodo para solução ou se os íons carregados se movem da solução para o eletrodo, uma vez que a corrente tem formalmente o mesmo sentido. Embora se trate de um fenômeno eletroquímico, em que a reação química implica na formação de um campo elétrico e este influencia a mesma, considerar-se-á no início, somente o processo químico, sendo posteriormente adicionado o efeito do campo elétrico. A medida que um íon se move para a superfície do eletrodo, sua energia potencial varia, e a transferência de carga ocorre depois que o íon positivo vence a energia de ativação necessária. Este mecanismo, similar ao fenômeno de difusão, mostra que a freqüência $(\vec{f})$ com que o íon salta a barreira de energia por difusão, é dada $\operatorname{por}^{78}$ :

$\overrightarrow{\mathrm{f}}=\frac{\mathrm{k}_{\mathrm{b}} \mathrm{T}}{\mathrm{h}} \mathrm{e}^{-\left(\Delta \overrightarrow{\mathrm{G}}^{0 *}\right) / \mathrm{RT}}$

onde $\mathrm{k}_{\mathrm{b}}$ é a constante de Boltzman, $\mathrm{h}$ a constante de Planck e $\Delta \mathrm{G}^{0}$, a variação de energia livre padrão necessária para o íon alcançar a energia de ativação quando o campo elétrico é nulo.

Ao multiplicarmos esta freqüência pela concentração do íon $\mathrm{A}^{+}\left(\mathrm{C}_{\mathrm{A}}^{+}\right)$na interface, obtém-se a velocidade de reação de redução em um campo elétrico nulo ${ }^{78}$ :

$\overrightarrow{\mathrm{v}}_{\mathrm{c}}=\frac{\Delta \mathrm{C}_{\mathrm{A}^{+}}}{\Delta \mathrm{t}}=\mathrm{C}_{\mathrm{A}^{+}} \frac{\mathrm{k}_{\mathrm{b}} \mathrm{T}}{\mathrm{h}} \mathrm{e}^{-\left(\Delta \overrightarrow{\mathrm{G}}^{0 *}\right) / \mathrm{RT}}$

A seta sobre $\mathrm{v}_{\mathrm{c}}$ indica que a reação é de redução e o índice c, que se trata de uma reação química em campo elétrico nulo. Esta expressão pode ser desmembrada em duas partes, uma dependente e outra independente da atividade, de acordo ${ }^{78}$ :

$\overrightarrow{\mathrm{v}}=\overrightarrow{\mathrm{k}}_{\mathrm{c}} \mathrm{C}_{\mathrm{A}^{+}}$

onde $\overrightarrow{\mathrm{k}}_{\mathrm{c}}$ é a freqüência com que as partículas da solução vencem a barreira de potencial (constante de velocidade), e $\mathrm{C}_{\mathrm{A}^{+}} \mathrm{O}$ número de espécies existentes em solução por unidade de área do eletrodo. 
Logo, no instante da imersão do eletrodo em uma solução eletrolítica, embora não haja ddp nem campo elétrico através da interface, esta pode não estar em equilíbrio, e neste caso uma reação de transferência de carga pode-ocorrer. Neste caso, a velocidade da reação de transferência de carga em campo elétrico nulo é determinada através de parâmetros cinéticos e químicos. No entanto, quando a reação de transferência de elétrons ocorre do eletrodo para espécie iônica receptora $\left(\mathrm{A}^{+}\right)$, o eletrodo adquire uma carga elétrica positiva e a solução negativa, dando início à interface eletrificada, à qual é equivalente a um capacitor, como descrito anteriormente. Esta separação de cargas na interface implica no desenvolvimento de uma ddp e o aparecimento de um campo elétrico. Como o campo elétrico afeta a velocidade do movimento das cargas, a velocidade da reação eletroquímica é afetada pelo campo na interface e a energia química transforma-se em eletroquímica. Considerando um íon positivo que passa da solução para o eletrodo, a energia livre de ativação química é dada por ${ }^{78}$.

$$
\Delta \overrightarrow{\mathrm{G}}^{0^{*}}=\Delta \overrightarrow{\mathrm{G}}_{\mathrm{C}}^{0^{*}}+\beta \mathrm{F} \Delta \phi
$$

onde o termo $\beta \mathrm{F} \Delta \phi$ é devido a energia elétrica, sendo $\beta$ o fator de simetria (número compreendido entre 0 e 1) e $\beta \Delta \phi$ é a fração da ddp na dupla camada e corresponde a passagem do íon da sua posição inicial até o ponto em que sua energia ultrapassa a barreira de energia de ativação, onde a reação ocorre espontaneamente.

Assim, a velocidade de redução pode ser escrita como:

$$
\begin{aligned}
& \overrightarrow{\mathrm{v}}_{\mathrm{e}}=\mathrm{c}_{\mathrm{A}^{+}} \frac{\mathrm{k}_{\mathrm{b}} \mathrm{T}}{\mathrm{h}} \mathrm{e}^{\left(-\Delta \overrightarrow{\mathrm{G}}^{0 *}\right) / \mathrm{RT}}=\mathrm{c}_{\mathrm{A}^{+}} \frac{\mathrm{k}_{\mathrm{b}} \mathrm{T}}{\mathrm{h}} \mathrm{e}^{-\frac{\left(\Delta \overrightarrow{\mathrm{G}}^{0^{*}}\right)+\beta \mathrm{F} \Delta \phi}{\mathrm{RT}}}=\overrightarrow{\mathrm{v}}_{\mathrm{c}} \mathrm{e}^{-\frac{\beta \mathrm{F} \Delta \phi}{\mathrm{RT}}}= \\
& =\mathrm{c}_{\mathrm{A}^{+}} \overrightarrow{\mathrm{k}}_{\mathrm{c}} \mathrm{e}^{-\frac{\beta \mathrm{F} \Delta \phi}{\mathrm{RT}}}=\mathrm{c}_{\mathrm{A}^{+}} \overrightarrow{\mathrm{k}}_{\mathrm{e}}
\end{aligned}
$$

onde o índice (e) indica a influência de um campo elétrico e $\overrightarrow{\mathrm{k}}_{\mathrm{e}}$ a constante de velocidade da reação eletroquímica.

A velocidade da reação eletroquímica representa o número de íons-grama que reagem por segundo atravessando a unidade de área da interface. Multiplicando esta velocidade, pela carga por mol, tem-se a densidade de corrente de redução $(\vec{I})$, ou melhor a quantidade de carga que passa por unidade de tempo e de área do eletrodo, de acordo $\operatorname{com}^{78}$ :

$$
\overrightarrow{\mathrm{I}}=\overrightarrow{\mathrm{v}}_{\mathrm{e}} \mathrm{F}=\mathrm{Fc}_{\mathrm{A}^{+}} \overrightarrow{\mathrm{k}}_{\mathrm{c}} \mathrm{e}^{-\frac{\beta \mathrm{F} \Delta \phi}{\mathrm{RT}}}
$$

sendo F a constante de Faraday.

Então, a Eq.19 estabelece a relação entre campo elétrico e a velocidade de transferência de elétrons através da interface. Sendo esta uma função exponencial, para pequenas variações no campo da interface, ocorre grande alteração no valor de densidade de corrente.

Em eletroquímica, o equilíbrio existente é dinâmico, onde os íons se movem da solução para o eletrodo e no sentido oposto. No início, a reação redox é mais deslocada num sentido e no equilíbrio as velocidades direta e reversa são iguais. Considerando que as cargas são sensíveis ao movimento, segundo o campo elétrico ou contra ele, se na reação de redução os íons positivos se movem contra o campo, para a reação reversa (oxidação) os íons movem-se com o campo. Logo, tem que se fornecer energia ao íon positivo para vencer uma $\operatorname{ddp}(\beta \Delta \phi)$ no sentido direto, enquanto em termos elétricos a espécie $B\left(C_{B}\right)$ passa espontaneamente gerando uma ddp $([1-\beta] \Delta \phi)$, na reação de oxidação. Assim, a velocidade de reação de oxidação e a densidade de corrente de oxidação são, respectivamente ${ }^{78}$ :
$\overline{\mathrm{v}}_{\mathrm{e}}=\mathrm{c}_{\mathrm{B}} \overline{\mathrm{k}}_{\mathrm{c}} \mathrm{e}^{\frac{(1-\beta) \mathrm{F} \Delta \phi}{\mathrm{RT}}}$

$\overrightarrow{\mathrm{I}}=\mathrm{Fc}_{\mathrm{B}} \overline{\mathrm{k}}_{\mathrm{c}} \mathrm{e}^{\frac{(1-\beta) \mathrm{F} \Delta \phi}{\mathrm{RT}}}$

No equilíbrio, as correntes de oxidação e redução se igualam e recebem a mesma designação, isto é, densidade de corrente de troca no equilíbrio $\left(\mathrm{I}_{0}\right)$.

Resumindo, no instante da imersão do eletrodo na solução eletrolítica, o campo elétrico é nulo, mas a medida que a reação de redução se processa, origina-se um campo elétrico que torna o eletrodo positivo e a solução negativa na interface. Contudo, ocorre a reação reversa, opondo-se ao aumento de cargas positivas no eletrodo. Caso não exista uma fonte externa de elétrons, atinge-se um compromisso entre as reações de redução e oxidação, havendo um valor de campo elétrico e de ddp onde as velocidades de perda e ganho de elétrons no eletrodo tornam-se iguais, assim como, as correntes de redução e oxidação. A interface metalsolução, no equilíbrio, não apresenta intensidade de corrente resultante, nem variação de potencial ou campo elétrico, ocorrendo apenas reações de oxidação e redução à mesma velocidade.

No entanto, quando há um fluxo resultante de elétrons, conseqüência do fato das correntes de redução e oxidação serem diferentes, este fluxo resultante é igual à transferência de cargas devido a cada uma das reações direta e reversa, implicando numa intensidade de corrente resultante e transformações químicas, indicando que a interface não está em equilíbrio. A intensidade de corrente resultante é dada pela diferença entre a densidade de corrente de oxidação e a de redução. Considerando que a ddp existente na dupla camada num estado de não-equilíbrio $\left(\mathrm{Df}_{\text {neq }}\right)$ é a soma de duas contribuições, uma devida ao potencial de equilíbrio $\left(\mathrm{Df}_{\mathrm{eq}}\right)$ e a outra a uma fonte extra $(\mathrm{h})$, que indica o quanto o potencial do eletrodo está afastado em relação ao seu valor no equilíbrio. Então, a densidade de corrente resultante pode ser descrita com base nas equações (19) e (21) nos seguinte termos ${ }^{78}$ :

$$
\mathrm{I}=\left\{\mathrm{Fc}_{\mathrm{B}} \overline{\mathrm{k}}_{\mathrm{c}}\left[\mathrm{e}^{\frac{(1-\beta) \mathrm{F} \Delta \phi}{\mathrm{RT}}}\right]\left[\mathrm{e}^{\frac{(1-\beta) \mathrm{F \eta}}{\mathrm{RT}}}\right]\right\}\left\{\mathrm{Fc}_{\mathrm{A}^{+}} \overrightarrow{\mathrm{k}}_{\mathrm{c}}\left[\mathrm{e}^{\frac{-\beta F \Delta \phi_{\mathrm{eq}}}{\mathrm{RT}}}\right]\left[\mathrm{e}^{\frac{-\beta F \eta}{\mathrm{RT}}}\right]\right\}
$$

ou

$I=\left\{I_{0}\left[e^{\frac{(1-\beta) F \eta}{R T}}\right]-\left[e^{\frac{-\beta F \eta}{R T}}\right]\right\}$

Esta é a equação de Butler-Volmer, que estabelece a densidade de corrente numa interface metal-solução dependente de $\mathrm{h}$, e da mesma forma como esta é exponencial, pequenas variações em $\eta$ causam grandes variações em I. Assim, em um sistema eletroquímico onde é aplicado potencial (célula eletrolítica), o potencial em excesso $\eta$ é a ddp que causa a corrente, enquanto num sistema oposto (célula galvânica), a corrente produzida através do circuito externo gera um potencial em excesso $\eta$. O termo sobretensão é usado para designar $\eta$ em qualquer sistema eletroquímico. Vale ressaltar que em ambos os casos, deve-se considerar uma ddp adicional (Ri) entre os eletrodos devido à passagem da corrente (i) através da solução. Assim, em uma célula eletrolítica com uma fonte de corrente contínua que faz passar corrente através da célula e dois eletrodos, a ddp desta, é a soma da ddp correspondente a primeira dupla camada elétrica, a passagem de corrente através da solução e aquela devido a segunda dupla camada elétrica. 
Agora, considerando um sistema eletroquímico no equilíbrio, a sobretensão $(\eta)$ é nula e a densidade de corrente resultante (I) também, assim, as densidades de corrente de oxidação e redução são iguais. Dividindo a equação (19) pela (21), tem-se:

$1=\frac{\mathrm{c}_{\mathrm{A}^{+}} \overrightarrow{\mathrm{k}}_{\mathrm{c}}}{\mathrm{c}_{\mathrm{B}} \overleftarrow{\mathrm{k}}_{\mathrm{c}}} \mathrm{e}^{-\frac{\mathrm{F} \Delta \phi_{\mathrm{eq}}}{\mathrm{RT}}}$

Aplicando o logaritmo natural à equação (24), tem-se:

$\Delta \phi_{\text {eq }}=\frac{\mathrm{RT}}{\mathrm{F}} \ln \frac{\overrightarrow{\mathrm{k}}_{\mathrm{c}}}{\mathrm{k}_{\mathrm{c}}}+\frac{\mathrm{RT}}{\mathrm{F}} \ln \frac{\mathrm{C}_{\mathrm{A}^{+}}}{\mathrm{C}_{\mathrm{B}}}$

O segundo termo da Eq. 25, o qual é função das constantes de velocidade de oxidação e redução da reação, é igual ao valor de $\Delta \phi$ quando a razão das concentrações $\mathrm{C}_{\mathrm{A}}{ }^{+} / \mathrm{C}_{\mathrm{B}}$ é igual a unidade, e então por conveniência, denominado de $\Delta \phi_{\mathrm{eq}}{ }^{0}$. Logo, a equação (25) torna-se:

$\Delta \phi_{\mathrm{eq}}=\Delta \phi_{\mathrm{eq}}^{0}+\frac{\mathrm{RT}}{\mathrm{F}} \ln \frac{\mathrm{C}_{\mathrm{A}^{+}}}{\mathrm{C}_{\mathrm{B}}}$

Esta é a expressão da Lei de Nernst para uma interface em equilíbrio. Contudo, como só se pode medir o potencial em uma célula eletroquímica, isto é, associando uma interface polarizável com outra não-polarizável, e considerando a concentração do metal como igual à unidade, a equação (26) torna-se:

$\Delta \mathrm{E}=\Delta \mathrm{E}^{0}+\frac{\mathrm{RT}}{\mathrm{F}} \ln \mathrm{C}_{\mathrm{A}^{+}}$

É importante lembrar que a concentração de uma espécie iônica em solução é afetada por uma propriedade denominada força iônica. Esta propriedade altera a capacidade reativa dos íons na solução devido às interações eletrostáticas (atração e repulsão) entre os mesmos, sendo mais pronunciada com o aumento da concentração. A capacidade reativa dos íons na solução é designada de atividade. A atividade do íon é relacionada com a concentração pelo coeficiente de atividade, o qual mede a eficiência com que uma espécie influencia um equilíbrio, no qual ela participa. Em soluções muito diluídas a força iônica é mínima e não afeta o comportamento dos íons na solução [80]. Além do efeito da força iônica, todas as deduções foram feitas para um íon em solução de carga unitária que sofre redução. Assim, deve-se adicionar à Eq. 27, o efeito da carga do íon (z), bem como o segundo termo na equação torna-se negativo quando o íon na solução está sofrendo oxidação. Então, a expressão geral da Lei de Nernst é dada por:

$\Delta \mathrm{E}=\Delta \mathrm{E}^{0} \pm \frac{\mathrm{RT}}{\mathrm{zF}} \ln \mathrm{a}_{\mathrm{A}^{\mathrm{z}}}$

onde $\mathrm{a}_{\mathrm{A}}$ é a atividade do íon em solução.

Vale ressaltar, que apesar da Eq. de Nernst estabelecer uma relação entre o potencial desenvolvido no eletrodo e a atividade do íon em solução, usualmente nos cálculos são utilizados as concentrações das soluções (Eq. 27). Isto é possível através de um artifício experimental, onde a força iônica das soluções medidas é mantida constante, embora a atividade não seja exatamente igual a concentração.

\section{A EQUAÇÃO DE NERNST A PARTIR DE PRINCÍPIOS TERMODINÂMICOS}

Antes de definir a equação de Nernst a partir de dados termodinâmicos, um importante conceito que se deve ter em mente é o de reversibilidade e irreversibilidade. Num sentido químico, uma reação é irreversível quando seus produtos, ou não reagem entre si, ou o fazem produzindo compostos diferentes dos reagentes iniciais. Em termos eletroquímicos, uma célula eletroquímica só ocorre em condições de reversibilidade termodinâmica quando uma pequena variação na força eletromotriz (fem) provoca a inversão da reação, o que pode ser obtido numa célula galvânica, opondo à sua fem espontânea, um potencial ligeiramente maior que este. A reversibilidade termodinâmica é um estado ideal do qual os sistemas reais podem se aproximar em certas condições. A principal delas é que a reação na célula eletroquímica seja cineticamente rápida, de modo a responder instantaneamente a qualquer variação de potencial $^{78}$. A definição de reversibilidade termodinâmica é baseada na descoberta que a quantidade de energia convertida em trabalho e liberada espontaneamente, depende da velocidade de reação. O trabalho máximo ocorre quando a velocidade da reação espontânea é infinitamente pequena. Quando a temperatura e a pressão se mantêm constante, o trabalho máximo que o sistema é capaz de fornecer é denominado de energia livre de Gibbs $(\Delta \mathrm{G})$. Em condições de reversibilidade termodinâmica, o trabalho máximo fornecido pelo sistema eletroquímico a pressão e temperatura constantes é igual a variação da energia livre de Gibbs, cuja a expressão pode ser obtida pela relação de Gibbs-Duhan ${ }^{78}$.

$-\Delta \mathrm{G}=\mathrm{zF} \Delta \mathrm{E}$

onde $\Delta \mathrm{G}$ é a mudança do potencial químico da solução; z é a carga do íon; F, a constante de Faraday (96485 Coulombs) e $\mathrm{E}$, o potencial elétrico.

Em uma célula eletroquímica reversível tem-se ${ }^{78}$.

$$
\Delta \mathrm{G}=\Delta \mathrm{G}^{0}+\mathrm{RT} \ln \frac{\mathrm{a}_{\mathrm{p}}}{\mathrm{a}_{\mathrm{r}}}
$$

onde $\mathrm{a}_{\mathrm{p}}$ é a atividade dos produtos e $\mathrm{a}_{\mathrm{r}}$ dos reagentes.

Substituindo (29) em (30), se obtém:

$$
-z F \Delta E==z F \Delta E^{0}+R T \ln \frac{a_{p}}{a_{r}}
$$

ou seja, a equação de Nernst (Eq. 28).

Cabe aqui ressaltar, que o potencial reversível da célula é calculado usando a atividade do íon no interior da solução e não na superfície do eletrodo.

\section{O TRANSPORTE DE MASSA NA SOLUÇÃO}

A constante cinética para a velocidade de reação no eletrodo (Eq. 17, no caso de redução), é influenciada não só pela reação no eletrodo, mas também pelo transporte de espécies do interior da solução para o eletrodo e vice-versa. Este transporte pode ocorrer por difusão, convecção e por migração. $\mathrm{O}$ efeito de migração normalmente é negligenciado pois o efeito do campo elétrico do eletrodo está limitado a distâncias muito pequenas da espécie ao eletrodo ${ }^{32}$. Assim, pode-se considerar que em condições de estado estacionário, o transporte das espécies é devido somente a difusão e a convecção. Existem dois tipos de convecção, a natural, devida a gradientes térmicos (em geral, negligenciável), e a forçada, associada aos mecanismos de transporte por fluxo. Em estado estacionário, o transporte de massa na solução deve-se principalmente ao fenômeno de difusão, que nada mais é, que o movimento natural (campo elétrico nulo) das espécies (carregadas ou neutras) na solução, devido a gradientes de concentração, sendo este comportamento expresso pela primeira e segunda lei de Fick ${ }^{32}$. Para um sistema de coordenada qualquer se tem: 
$\mathrm{J}=-\mathrm{D} \nabla \mathrm{c}$

$$
\frac{\partial \mathrm{c}}{\partial \mathrm{t}}=\mathrm{D} \nabla^{2} \mathrm{c}
$$

onde $\mathrm{J}$ é o fluxo de espécies, $\nabla$ é denominado operador del, sendo $\nabla^{2}$ o operador de Laplace, e D uma constante denominada de coeficiente de difusão, cujo valor em solução aquosa varia entre $10^{-5}$ à $10^{-6} \mathrm{~cm}^{2} \mathrm{~s}^{-1}$.

Um importante fundamento para eletroquímica, que advém do transporte por difusão é o conceito de camada de difusão, que é o gradiente de concentração na superfície do eletrodo definido pela equação:

$$
\mathrm{D}\left(\frac{\partial_{\mathrm{c}}}{\partial_{\mathrm{x}}}\right)_{0}=\mathrm{D} \frac{\left(\mathrm{c}_{\infty}-\mathrm{c}_{0}\right)}{\delta_{\mathrm{d}}}
$$

onde $\mathrm{C}_{\infty}$ representa a concentração no interior da solução, $\mathrm{C}_{0}$ a concentração no eletrodo e $\delta_{\mathrm{d}}$ a espessura da camada de difusão.

A espessura da camada de difusão $\left(\delta_{d}\right)$, normalmente é associada com o coeficiente de transferência de massa $\left(\mathrm{k}_{\mathrm{d}}\right)$ pela expressão:

$\mathrm{k}_{\mathrm{d}}=\frac{\mathrm{D}}{\delta_{\mathrm{d}}}$

Uma clara observação da Eq. 35, é que quanto menor a espessura da camada de difusão, maior é o gradiente de concentração na superfície do eletrodo, situação ideal que conduz a um sinal mais elevado, seja de corrente em voltametria ou potencial em potenciometria. Esta condição ideal, isto é, uma pequena espessura da camada de difusão, é obtida em sistemas hidrodinâmicos onde a convecção forçada é responsável pelo transporte de massa.

Num sistema hidrodinâmico a convecção e a difusão contribuem significativamente para o transporte de massa, sendo a primeira e a segunda lei de Fick, modificadas para ${ }^{32}$ :

$\mathrm{J}=\mathrm{cv}-\mathrm{D} \nabla \mathrm{c}$

$\frac{\partial_{c}}{\partial_{t}}=-v \nabla c+D \nabla^{2} c$

onde $v$ é a componente de velocidade, que para um sistema de três coordenadas cartesianas é dado por $\mathrm{v}_{\mathrm{x}}+\mathrm{v}_{\mathrm{y}}+\mathrm{v}_{\mathrm{z}}$. Este perfil de velocidade varia com o tipo de escoamento, dependendo do regime ser laminar, de transição ou turbulento.

Nos sistemas hidrodinâmicos, além da camada de difusão existe uma camada denominada hidrodinâmica de espessura $\mathrm{d}_{\mathrm{H}}$, onde ocorre todos os gradientes de velocidade. Levich ${ }^{76}$ relacionou a espessura da camada hidrodinâmica com a espessura da camada de difusão pela expressão:

$\delta_{\mathrm{d}} \approx\left(\frac{\mathrm{D}}{\mathrm{v}}\right)^{\frac{1}{3}} \delta_{\mathrm{H}}$

Em solução aquosa o coeficiente de difusão, $\mathrm{D} \cong 10^{-5} \mathrm{~cm}^{2} \mathrm{~s}^{-1}$, e a viscosidade cinemática, $v \cong 10^{-2} \mathrm{~cm}^{2} \mathrm{~s}^{-1}$, o que indica que $\delta_{\mathrm{d}} \cong 0,1 \delta_{\mathrm{H}}$, o que vale supor que não há convecção dentro da camada de difusão.

Com base nesses conceitos o processo global responsável pela formação da dupla-camada elétrica e conseqüentemente da resposta de um ISE é devido a duas componentes, a cinética descrita pela constante de velocidade de reação do eletrodo e a de transporte, definida pelo coeficiente de transferência de massa $\left(k_{d}\right)$, que descreve a velocidade das espécies carregadas dentro da camada de difusão ${ }^{32}$.

$\Delta \mathrm{E}=\Delta \mathrm{E}^{0} \pm \frac{2,303 \mathrm{RT}}{\mathrm{z}_{\mathrm{a}} \mathrm{F}} \log \left(\mathrm{a}_{\mathrm{A}} \sum_{\mathrm{B}} \mathrm{K}_{\mathrm{a}, \mathrm{b}}^{\mathrm{POT}} \mathrm{a}_{\mathrm{B}}^{\mathrm{z}_{\mathrm{A}} / \mathrm{z}_{\mathrm{B}}}\right)$

\section{SELETIVIDADE DOS ELETRODOS POTENCIOMÉTRICOS}

No início do surgimento dos eletrodos potenciométricos, a comunidade científica considerou que eles eram específicos. Contudo, com o passar do tempo, os pesquisadores começaram a descobrir que a especificidade dos sensores potenciométricos não era tão grande como se pensava e o termo seletivo foi consagrado, em substituição ao específico. Em potenciometria é bem conhecido o estudo de interferentes, através da determinação dos coeficientes de seletividade potenciométricos $\left(\mathrm{K}^{\mathrm{POT}}\right)$ pelos métodos da interferência fixa ou das soluções separadas, na qual estes coeficientes são obtidos pela equação de Nicolsky-Eisenman $(\mathrm{N}-\mathrm{E})^{9,10,80}$ :

$\mathrm{a}_{\mathrm{A}}=\mathrm{K}_{\mathrm{A}, \mathrm{B}}^{\mathrm{POT}} \mathrm{a}_{\mathrm{B}}^{\mathrm{z}_{\mathrm{A}} / \mathrm{z}_{\mathrm{B}}}$

A partir desta equação, pode-se determinar o $\mathrm{K}^{\mathrm{POT}}$. Quando ambos os íons, primário (A) e interferente (B) contribuem igualmente para a resposta do eletrodo tem-se:

$\Delta \mathrm{E}=\Delta \mathrm{E} \pm \frac{2,303 \mathrm{RT}}{\mathrm{z}_{\mathrm{A}} \mathrm{F}} \log \left(2 \mathrm{a}_{\mathrm{A}}\right)$

Considerando que ambos os íons apresentam a mesma carga, pode-se substituir a Eq. 40 na 39, e então se tem:

$\Delta \mathrm{E}= \pm \frac{2,303 \mathrm{RT}}{\mathrm{z}_{\mathrm{A}} \mathrm{F}}\left(\log 2 \mathrm{a}_{\mathrm{A}}-\log \mathrm{a}_{\mathrm{A}}\right)$

Logo, a diferença entre os potenciais do eletrodo em solução de A com e sem B é dada por:

$\Delta \mathrm{E}= \pm \frac{2,303 \mathrm{RT}}{\mathrm{z}_{\mathrm{A}} \mathrm{F}}(\log 2)$

$\Delta \mathrm{E} \approx \pm \frac{18}{\mathrm{z}_{\mathrm{A}}} \mathrm{mV}$ a $25^{\circ} \mathrm{C}$

Então, determina-se graficamente a atividade de A, na qual a curva analítica difere da extrapolação da região linear por $18 / \mathrm{z}_{\mathrm{A}}$. Pela substituição deste valor na Eq. 40 obtém-se o $\mathrm{K}^{\mathrm{POT}}$. Assim, quando um eletrodo é muito seletivo para A em relação a $\mathrm{B}, \mathrm{o} \mathrm{K}^{\mathrm{POT}}$ deverá ser muito menor que a unidade. Contudo, a equação de N-E apresenta uma série de limitações. A primeira delas ocorre quando a carga do íon primário (A) é diferente da do interferente (B). Se a carga de A for menor, o coeficiente de seletividade determinado é extremamente baixo, indicando pequena interferência e vice-versa. Isto se deve a relação exponencial do $\mathrm{K}^{\mathrm{POT}}$ com a carga do íon, assim, o $\mathrm{K}^{\mathrm{POT}}$ determinado desta maneira apresenta quase sempre valores fora da realidade com os dados experimentais, não possuindo significado prático. Outro problema da equação de N-E é a forma simétrica com que o eletrodo responde para o íon primário e o interferente, assumindo resposta nernstiana também para o íon 
interferente. Assim, a União Internacional de Química Pura e Aplicada (IUPAC) recomenda como método para calcular o $\mathrm{K}^{\mathrm{POT}}$ de um sensor potenciométrico, o do potencial-equivalente (matched-potential) ${ }^{81}$. Este método, proposto por Gadzekpo e Christian ${ }^{82}$ consiste em determinar a concentração para o íon interferente na qual a variação de potencial é a mesma para uma dada concentração do íon primário em uma solução de referência. As características principais do método do potencial-equivalente são:

“ a carga do íon primário e do interferente não é levada em consideração;

“ este método não assume resposta nernstiana para o íon primário nem para o interferente.

Estas características conferem ao método do potencial-equivalente maior significado prático, que aquele em que se aplica a equação de N-E. Então, o $\mathrm{K}^{\mathrm{POT}}$ pelo método do potencialequivalente pode ser obtido pela equação:

$\mathrm{K}_{\mathrm{A}, \mathrm{B}}^{\mathrm{POT}}=\frac{\mathrm{a}_{\mathrm{A}}^{\prime}-\mathrm{a}_{\mathrm{A}}}{\mathrm{a}_{\mathrm{B}}}$

onde, $\mathrm{a}_{\mathrm{A}}$ é a atividade onde eletrodo começa a responder linearmente para o íon primário (A); $a_{B}$ é a atividade do íon interferente que dá o mesmo potencial de uma determinada atividade do íon primário $\left(\mathrm{a}_{\mathrm{A}}\right)$, previamente estabelecida.

É importante ressaltar, que o método do potencial-equivalente é do ponto de vista prático, conveniente, pois é simples de calcular e experimentalmente fácil de realizar. Contudo, os coeficientes obtidos não podem ser utilizados para obter valores para a atividade do íon primário em soluções desconhecidas. Assim, este método serve apenas como um guia para indicar o grau de seletividade de um ISE, não podendo ser utilizado de maneira quantitativa. Além disto, não existe nenhuma associação deste método com as teorias estabelecidas sobre o mecanismo de resposta de um ISE.

\section{RECENTES AVANÇOS E O FUTURO DA POTENCIOMETRIA}

Após a descoberta dos ISFET parecia que a era dos eletrodos íon-seletivos chegara ao fim. Contudo, ainda hoje os ISE têm sido extensivamente estudados. Em 1990, vinte anos após o surgimento dos ISFET, mais de 7000 trabalhos foram publicados sobre aplicações de ISE ${ }^{5}$, indicando que esta metodologia ainda não pode ser considerada inteiramente esgotada. As mais recentes novidades na área ocorreram com a proposta dos eletrodos de estado sólido reversíveis baseados em derivados de ftalocianina de cobalto ${ }^{83-85}$. Estes sensores foram desenvolvidos para determinação de sulfeto $^{83}$, nitrito ${ }^{84}$, ácido ascórbico ${ }^{85-}$ ${ }^{87}$, cisteína ${ }^{85}$, dentre outras espécies redox. O princípio de funcionamento destes sensores baseia-se na mudança de densidade de carga na superfície do eletrodo devido a redução dos íons $\mathrm{Co}^{2+}$ para $\mathrm{Co}^{1+}$ por um agente redutor, sendo o eletrodo restaurado pelo oxigênio dissolvido na solução, que é continuamente borbulhado. Similarmente, eletrodos de membrana baseados em poli(etileno co-acetato de vinila) dopado com íons $\mathrm{Cu}^{2+}$ foram propostos para detecção de ácido ascórbico ${ }^{88,89}$ e dopamina $^{90}$. O problema deste tipo de sensor é o longo tempo necessário para restauração do mesmo, em geral, 10 à 15 min quando se utiliza o oxigênio. Contudo, esta limitação tem sido superada utilizando peróxido de hidrogênio na restauração da atividade do eletrodo, permitindo que estes sensores possam ser empregados associados a técnicas dinâmicas de análise, como FIA ${ }^{89,90}$.

Em relação ao futuro da potenciometria, este tem como promessa o uso de ISE como ferramenta em análises clínicas in situ, usando microeletrodos e conjunto destes. Apesar desta idéia ser antiga ela ainda não se cumpriu, embora exista muita pesquisa ativa nesta área ${ }^{91-94}$. Vantagens como confiabilidade, robustez, seletividade e sensibilidade, faz dos ISE, uma importante metodologia que pode ser aplicada a ensaios clínicos e industriais diretamente. Embora a potenciometria tenha completado mais de cem anos, muitos aspectos sobre o mecanismo de resposta dos ISE e principalmente, sobre a sua seletividade ainda não foram inteiramente compreendidos. Isto é um incentivo para o desenvolvimento de novos modelos teóricos, provavelmente centrados, não nos aspectos termodinâmicos da equação de Nernst, mas na teoria dos capacitores. Além disto, o conceito de coeficiente de seletividade dos ISE, ainda não foi completamente elucidado, apesar do método do potencialequivalente ter contribuído para isto. O problema ainda ocorre devido ao valor de $\mathrm{K}^{\mathrm{POT}}$ não ser constante e depender das atividades dos íons primário e interferente utilizadas na medida do mesmo. Alguns pesquisadores têm sugerido para determinação dos coeficientes de seletividade de ISE, o uso da teoria do planejamento experimental ${ }^{95}$, calibração multivariada ${ }^{96}$ e métodos matemáticos de ajuste de curva não-linear ${ }^{97}$. Outras propostas para determinar o $\mathrm{K}^{\mathrm{POT}}{ }^{98-100}$ se baseiam na teoria do potencial na fase-limite ${ }^{101}$ e consiste em obter as condições matemáticas necessárias para que o eletrodo responda nernstianamente para os íons primário e interferente. Alguns métodos mais recentes, utilizam algoritmos derivados da equação de Nickolsky-Eisenman onde a presença de vários íons interferentes e a resposta dos íons misturados ou o comportamento "real" do eletrodo são levados em consideração ${ }^{102,103}$.

Assim, estudos na direção das funções resposta-seletividade para os ISE, podem ser um novo caminho para a potenciometria, revitalizando esta metodologia.

\section{AGRADECIMENTOS}

Os autores agradecem ao auxílio financeiro concedido pela FAPESP.

\section{REFERÊNCIAS}

1. Nernst, W.; Loeb, K.; Z. Phys. Chem. 1888, 2, 948.

2. Nernst, W.; Ber. Deutsch. Chem. Ges. 1897, 30, 1547.

3. Cremer, M.; Z. Biol. 1906, 47, 562.

4. Haber, F.; Klemensiewicz, Z.; Z. Phys. Chem. 1909, 67,385

5. Ruzicka, J.; J. Chem. Educ. 1997, 74, 167.

6. Beckman, A. O.; Hexagon 1987, 78, 41.

7. Radiometer Annual Report, Copenhagen, 1994/1995

8. Elder, L. W.; Wright, W. H.; Proc. Natl. Acad. Sci. U.S.A. 1928, 14, 938

9. Eisenman, G.; Ruskin, D. C.; Casby, J. H.; Science 1957, 126,831 .

10. Nikolski, B. P.; Schultz, M. M.; Zh. Fiz. Khim. 1962, $36,704$.

11. Ross, J. W.; Belgian Patent 668, 409, 1966. Chem. Abstr. 1966, 65, 5032a.

12. Frant, M.; Ross, J. W.; Science 1966, 154, 1553.

13. Ross. J. W.; Science 1967, 156, 1378

14. Stefanec, Z.; Simon, W.; Chimia 1966, 20, 436.

15. Stefanec, Z.; Simon, W.; Microchem. J. 1967, 12, 125.

16. Moody, G. J.; Oke, R. B.; Thomas, J. D. R.; Analyst 1970, 95, 910.

17. Clark, L. C.; Lyons, C.; Ann. N. Y. Acad. Sci. 1962, 102, 29.

18. Bergveld, P.; IEEE T. Bio-Med Eng. 1970, BM 17, 70.

19. Janata, J.; Analyst 1994, 119, 2275.

20. Thomas, J. D. R.; Analyst 1994, 119, 203.

21. Frant, M. S.; Analyst 1994, 119, 2293.

22. Frant, M. S.; J. Chem. Educ. 1997, 74, 159.

23. Pungor, E.; Fres. J. Anal. Chem. 1997, 357, 184.

24. Stock, J. T.; Orna, M. V.; Electrochemistry, Past and Present, American Chemical Society, Washington, DC, 
1989. Cheng, K. L.; $p H$ Glass Electrode and Its Mechanism, Chapter 20, pp. 286.

25. Astrup, P.; Severinghaus, J. W.; The History of Blood Bases, Acids and Bases, Mungsgaard Int.: Copenhagen, 1986.

26. Donnan, F. G.; Z. Elektrochem. 1911, 17, 572.

27. Horovitz, K.; Z. Physik. 1923, 15, 369.

28. Nikolski, B. P.; Acta Physicochim USSR 1937, 7, 797.

29. Teorell, T.; Proc. Soc. Exp. Bio. Med. 1935, 33, 282.

30. Meyer, K. H.; Sievers, J. F.; Helv. Chim. Acta 1936, 19, 649, 665, 987.

31. Pungor, E.; Tóth, K.; Analyst 1970, 95, 625.

32. Brett, A. M. O.; Brett, C. M. A.; Electroquímica - Princípios, Métodos e Aplicações, Oxford University Press, Inc., Livraria Almedina, Coimbra, 1996.

33. Von Helmholtz, H. L. F.; Ann. Physik 1853, 89, 211.

34. Von Helmholtz, H. L. F.; Ann. Physik 1879, 7, 337.

35. Bockris, J. O'M.; Reddy, A. K. N.; Modern Electrochemistry - An Introduction to an Interdisciplinary Area, Plenum Press, New York, $3^{\text {rd }}$, Vol. 1 and 2, 1977.

36. Gouy, G.; Comp. Rend. 1910, 149, 654.

37. Chapman, D. L.; Phil. Mag. 1913, 25, 475.

38. Stern, O.; Z. Elektrochem. 1924, 30, 508.

39. Grahame, D. C.; Chem. Rev. 1947, 41, 441.

40. Bockris, J. O’M.; Devanathan, M. A.; Müller, K.; Proc. R. Soc. 1963, A274, 55.

41. Damaskin, B. B.; Frumkin, A. N.; Electrochim. Acta 1974, 19, 173.

42. Gonzales, R.; Sanz, F.; Electroanalysis 1997, 9, 169.

43. Damanski, B. B.; Grafov, B. M.; Russian J. Electrochem. 1998, 34, 967.

44. Hirata, Y.; Mizutani, F.; Yokoyama, H.; Surf. Interf. Anal. 1999, 27, 317.

45. Behrens, S. H; Borkovec, M.; J. Phys. Chem. B 1999, 103, 2918.

46. Das, D.; Senapati, S.; Chandra, A.; J. Chem Phys. 1999, $110,8129$.

47. Lamperski, S.; Outhwaite, C. W.; J. Electroanal. Chem. 1999, 460, 135.

48. Mattke, T.; Kecke, H. J.; J. Coll. Interf. Sc. 1998, 208, 555.

49. Fawcett, W. R.; Kloss, A. A.; Calvente, J. J.; Marinkovic, N.; Electrochim. Acta 1998, 44, 881.

50. Buck, R. P.; Ion-sel. Electrode Rev. 1982, 4, 3.

51. Armstrong, R. D.; Lockhart, J. C.; Todd, M.; Electrochim. Acta 1986, 31, 591.

52. Sie, S.; Camman, K.; J. Electroanal. Chem. 1987, 229, 249.

53. Horvai, G.; Gráf, E.; Tóth, K.; Pungor, E.; Buck, R. P.; Anal. Chem. 1986, 38, 2735.

54. Tóth, K.; Gráf, E.; Horvai, G.; Pungor, E.; Buck, R. P.; Anal. Chem. 1986, 58, 2741.

55. Cammann, K.; Rechnitz, G. A.; Anal. Chem. 1976, 48, 856.

56. Cammann, K.; Anal. Chem. 1978, 50, 436.

57. Iglehart, M. L.; Buck, R. P.; Pungor, E.; Anal. Chem. 1988, 60, 290.

58. Iglehart, M. L.; Buck, R. P.; Horvai, G.; Pungor, E.; Anal. Chem. 1988, 60, 1018.

59. Koryta, J.; Electrochim. Acta 1979, 24, 293.

60. Vanisek, P.; Ruth, W.; Koryta, J.; J. Electroanal. Chem. $1983 ; 148,117$.

61. Demoz, A.; Verpoorte, E. M. J.; Harrison, D. J.; J. Electroanal. Chem. 1995, 38, 971.

62. Tóth, K.; Gavallér, I. G.; Pungor, E.; Anal. Chim. Acta 1971, 57, 131.

63. Horvai, G.; Toth, K.; Pungor, E.; Anal. Chim. Acta 1989, $216,163$.
64. Pungor, E.; Electroanalysis 1996, 83, 48.

65. Buck, R. P.; Hung Sci. Instrum. 1980, 49, 7.

66. Giolito, I.; Métodos Eletrométricos e Eletroanalíticos Fundamentos e Aplicações, Multitec, São Paulo, 2a edição, 1980.

67. Haugaard, G.; J. Phys. Chem. 1941, 45, 148.

68. Schwabe, K.; Dahms, H.; Z. Elektrochem. 1961, 65, 518.

69. Eisenman, G.; Biophys. J. 1962, 2, 259.

70. Lengyel, B. V.; Physik, S.; Chem. Abt. A 1931, 153, 425.

71. Horváth, V.; Horvai, G.; Pungor, E.; Fres. J. Anal. Chem. 1993, 346, 569.

72. Pungor, E.; Microchem. J. 1997, 57, 251.

73. Pungor, E.; Fres. J. Anal. Chem. 1997, 357, 184.

74. Pungor, E.; Talanta 1997, 44, 1505.

75. Pungor, E.; Anal. Sc. 1998, 14, 249.

76. Pungor, E.; Pure \& Appl. Chem. 1992, 64, 503.

77. Cheng, K. L.; Chang, H.; Mikrochim. Acta 1985, I, 95.

78. Gonçalves, M. L. S. S.; Métodos Instrumentais para Análise de Soluções - Análise Quantitativa, Fundação Calouste-Gulbenkian, Lisboa, 1983.

79. Levich, V. G.; Physicochemical hydrodinamics, PrenticeHall, Englewood Cliffs, NJ, 1962.

80. Bailey, P. L.; Analysis with Ion-selective Electrodes, Second Edition, London, 1980.

81. Umezawa, Y.; Umezawa, K.; Sato, H.; Pure \& Appl. Chem. 1995 , 67, 507.

82. Gadzekpo, V. P. Y.; Christian, G. D.; Anal. Chim. Acta 1984, 164, 279.

83. Tse, Y.; Janda, P.; Lever, A. B. P.; Anal. Chem. 1994, $66,384$.

84. Li, J.; Pang, X.; Yu, R.; Anal. Chim. Acta 1994, 297, 437.

85. Li, J.; Shen, G.; Yu, R.; Analyst 1995, 120, 2259.

86. Janda, P.; Weber, J.; Dunsch, L.; Lever, A. B. P.; Anal. Chem. 1996, 68, 960.

87. Li, J.; Hu, M.; Yu, R.; Sensors Actuators B 1996, 30, 65.

88. Fernandes, J. C. B.; Kubota, L. T.; Neto, G. O.; Electroanalysis 1999, 11, 475.

89. Fernandes, J. C. B.; Rover, L.; Kubota, L. T.; Neto, G. O.; J. Braz. Chem. Soc. 2000, 11, 182.

90. Rover, L.; Fernandes, J. C. B.; Neto, G. O.; Kubota, L. T.; J. Eletroanal. Chem. 2000, 481, 34.

91. Knoll, M.; Cammann, K.; Dumschat, C.; Eshold, J.; Sundermeier, C.; Sensors Actuators B 1994, 21, 71.

92. Dumschat, C.; Borchardt, M.; Diekmann, C.; Cammann, K.; Knoll, M.; Sensors Actuators B 1995, 24-25, 279.

93. Borchardt, M.; Dumschat, C.; Cammann, K.; Knoll, M.; Sensors Actuators B 1995, 24-25, 721.

94. Lynch, A.; Diamond, D.; Lemoine, P.; McLaughlin, J.; Leader, M.; Electroanalysis 1998, 10, 1096.

95. Parczewski, A.; Madej, A.; Chem. Anal. 1982, 27, 133.

96. Diamond, D.; Forster, R. J.; Anal. Chim. Acta 1993, 276, 75.

97. Kane, P.; Diamond, D.; Talanta 1997, 44, 1847.

98. Bakker, E.; Meruva, R. K.; Pretsch, E.; Meyerhoff, M. E.; Anal. Chem. 1994, 66, 3021.

99. Bakker, E.; Anal. Chem. 1997, 69, 1061.

100. Nägele, M.; Bakker, E.; Pretsch, E.; Anal. Chem. 1999, 71,1041

101. Karpfen, F. M.; Randles, J. E. B.; Trans. Faraday Soc. 1953, 49, 823.

102. Zhang, W.; Fakler, A.; Demuth, C.; Spichiger, U. E.; Anal. Chim. Acta 1998, 375, 211.

103. Deyhimi, F.; Talanta 1999, 50, 1129. 